\title{
Human glutamate dehydrogenase is immunologically distinct from other mammalian orthologues
}

\author{
Sang Ho Jang ${ }^{1}$, A Yeon Kim ${ }^{1}$, \\ Jae Hoon Bahn ${ }^{1,6}$, Won Sik Eum ${ }^{1}$, \\ Dae Won Kim ${ }^{1}$, Jinseu Park ${ }^{1}$, Kil Soo Lee ${ }^{1}$, \\ Tae-Cheon Kang ${ }^{2}$, Moo Ho Won ${ }^{2}$, \\ Jung Hoon Kang ${ }^{3}$, Oh-Shin Kwon ${ }^{4}$, \\ Hae-Young Yoon ${ }^{5}$, Eun-Young Lee ${ }^{5}$, \\ Sung-Woo $\mathrm{Cho}^{5}$ and Soo Young Choi ${ }^{1,7}$ \\ ${ }^{1}$ Department of Genetic Engineering \\ Division of Life Sciences \\ ${ }^{2}$ Department of Anatomy, College of Medicine \\ Hallym University, Chunchon 200-702, Korea \\ ${ }^{3}$ Department of Genetic Engineering \\ Chongju University, Chongju 360-764, Korea \\ ${ }^{4}$ Department of Biochemistry \\ Kyungpook National University, Daegu 702-701, Korea \\ ${ }^{5}$ Department of Biochemistry and Molecular Biology \\ College of Medicine, University of Ulsan \\ Seoul 138-736, Korea \\ ${ }^{6}$ Present address: Department of Cellular Molecular and \\ Developmental Biology, University of Tennessee \\ Knoxville, Tennessee 37916, USA \\ ${ }^{7}$ Corresponding author: Tel, 82-33-248-2112; \\ Fax, 82-33-241-1463; E-mail, sychoi@hallym.ac.kr
}

Accepted 29 May 2003

Abbreviations: hGDH, human glutamate dehydrogenase; mAbs, monoclonal antibodies; TBS, Tris-buffered saline

\begin{abstract}
Five monoclonal antibodies ( $m A b s$ ) that recognize human glutamate dehydrogenase (GDH) have been selected and designated as monoclonal antibodies hGDH60-6, hGDH60-8, hGDH63-10, hGDH63-11, and hGDH91-14. A total of five mAbs recognizing different epitopes of the enzyme were obtained, two of which inhibited human GDH activity. When total proteins of human homogenate separated by SDSPAGE, were probed with $m A b s$, a single reactive protein band of $55 \mathrm{kDa}$, which co-migrated with purified recombinant human GDH was detected. When the purified GDH was incubated with each of the mAbs, its enzyme activity was inhibited by up to $58 \%$. Epitope mapping analysis identified,
\end{abstract}

two subgroups of mAbs recognizing different peptide fragments. Using the individual anti-GDH antibodies as probes, the cross reactivities of brain GDH obtained from human and other animal brain tissues were investigated. For the human and animal tissues tested, immunoreactive bands on Western blots appeared to have the same molecular mass of $55 \mathrm{kDa}$ when hGHD60-6, hGHD60-8, or hGHD91-14 mAbs were used as probes. However, the anti-human GDH mAbs immunoreactive to bands on Western blots reacted differently on the immunoblots of the other animal brains tested, i.e., the two monoclonal antibodies hGDH63-10 and hGDH63-11 only produced positive results for human. These results suggest that human brain GDH is immunologically distinct from those of other mammalian brains. Thorough characterization of these anti-human GDH mAbs could provide potentially valuable tool as immunodiagnostic reagents for the detection, identification and characterization of the various neurological diseases related to the GDH enzyme.

Keywords: cross-reactivity; epitope mapping; human glutamate dehydrogenase; immunoblot; monoclonal antibodies

\section{Introduction}

Glutamate dehydrogenase (GDH) (EC 1.4.1.3) catalyzes the reversible deamination of 1-glutamate to 2-oxoglutarate using $\mathrm{NAD}^{+}$or $\mathrm{NADP}^{+}$as coenzyme (Smith et al., 1975). GDH has long been used as a marker for mitochondria in brain and other tissues. However, the activity of GDH is also enriched in the nuclear fraction as well as in the mitochondria fraction (Lai et al., 1986). Recent biochemical works led to the finding that multiple forms of GDH are present in mammalian system and that the activities of the GDH isotypes differ in their relative resistance to thermal inactivation, detergent extractability, and allosteric regulation characteristics (Plaitakis et al., 1984; 2000; Abe et al., 1992; Cho et al., 1995; Shashidharan et al., 1997). These forms have been designated soluble and particulate GDH (Plaitakis et al., 1984; Colon et al., 1986; Hussain et al., 1989). Although many studies show the subcellular localization of GDH (Schmitt and Kugler, 1999), the origin of the GDH polymor- 
phism is not known. It was reported that the presence of four differently sized mRNAs and multiple gene copies for GDH occur in the human brain (Plaitakis et al., 1993). A novel cDNA encoded by an X chromosome-linked intronless gene also has been isolated from human retina (Shashidharan et al., 1994; 1997). The importance of the GDH-deficient neurological disorders has attracted considerable interest. Four different forms of GDH isoproteins were detected from the human cerebellum of normal subjects and patients with neurodegenerative disorders (Duvoisin et al., 1983; Plaitakis et al., 1984; Hussain et al., 1989). The GDH isoproteins are differentially distributed in the two catalytically active isoforms of the enzyme (Colon et al., 1986; Plaitakis et al., 1993). The enzyme isolated from one of the patients with a variant form of multisystem atrophy displayed a marked reduction of one of the GDH isoproteins (Hussain et al., 1989). However, it is not known whether the distinct properties of the GDH isoproteins are essential for the regulation of glutamate metabolism. At present, the functional significance and reaction mechanism of GDH isotypes in nerve tissue remains to be studied. Recently, we isolated two soluble forms of GDH isoproteins (designated GDHI and GDHII) from bovine brain, and the GTP binding site within the GDH isoproteins were identified by using photoaffinity labeling (Cho et al., 1995; 1996; 1998). The results from our recent studies in brain demonstrate that the bovine brain GDH isoproteins are different gene products rather than the results of posttranslational modifications (Cho et al., 1995; 1998). We also identified an essential lysine residue by using o-phthalaldehyde, pyridoxal 5'-phosphate (PLP) and peptide analysis (Kim et al., 1997; Ahn et al., 1999). More recently, we synthesized and expressed the human GDH gene and identified the GTP binding site by the cassette mutagenesis and photoaffinity labeling (Lee et al., 2001; Yoon et al., 2002).

In the present study, the recombinant human enzyme was injected as an immunogen into BALB/C mice to obtain monoclonal antibodies (mAbs), and five $\mathrm{mAbs}$ to the protein were produced from the fusion experiments. The mAbs, which specifically recognized human GDH on Western blots, were characterized and used as probes for a cross-reactivity study of the brain enzymes from human, and other mammalian sources. In addition, we identified the cross reactivities with various rat tissues and tumor cell lines.

\section{Materials and Methods}

\section{Materials}

NADH, bovine serum albumin, L-glutamate, EDTA, phenylmethylsulfonyl fluoride, 2-oxoglutarate, ADP,
Sephadex G-100 and G-200 were purchased from Pharmacia LKB. ammonium acetate, 2-mercaptoethanol, and goat anti-mouse $\lg G$ conjugated with horseradish peroxidase (HRP) were purchased from Sigma. Basal medium Eagle, Dulbecco's Modified Eagle's (DME) medium, hypoxanthine-aminopterin-thymidine (HAT), polyethylene glycol (PEG) for fusion and penicillin/streptomycin antibiotics were purchased from GIBCO BRL. Goat anti-mouse IgG conjugated with alkaline phosphatase (AP) and conjugated with horseradish peroxidase (HRP) was obtained from Santa Cruz. Dialysis tubing was purchased from Sigma. Hybond $-\mathrm{C}^{+}$nitrocellulose membrane and $\mathrm{ECL}$ western blotting detection reagent were purchased from Amersham. All other reagents were of the highest purity available.

\section{Enzyme purification}

Human GDH gene (pHGDH) has been chemically synthesized and overexpressed as a soluble protein in E. coli as previously described (Cho et al., 2001). E. coli BL21 (DE3) was used for high level expression of the recombinant human GDH. Purification of human GDH was performed with a slight modification of the previous methods (Cho et al., 1995).

Fresh overnight cultures of $\mathrm{DE} 3 / \mathrm{pHGDH}$ at $37^{\circ} \mathrm{C}$ were used to inoculate $1 \mathrm{~L}$ of LB containing ampicillin. After the cells had grown until the $A_{600}$ reached 1.0 and then IPTG was added to a final concentration of $1 \mathrm{mM}$, and the incubation was continued for $3 \mathrm{~h}$. The cells were harvested by centrifugation. Cell pellets were suspended in $100 \mathrm{ml}$ of $100 \mathrm{mM}$ Tris- $\mathrm{HCl}(\mathrm{pH}$ 7.4), $1 \mathrm{mM}$ EDTA, $5 \mathrm{mM}$ dithiothreitol and lysed with a sonicator. Cellular debris was removed by centrifugation and the crude extract was precipitated by 30 $65 \%$ ammonium sulfate. After centrifugation at 12,000 $g$ for $30 \mathrm{~min}$ at $4^{\circ} \mathrm{C}$, the pellet was dissolved in a minimum amount of buffer $A$ (2 $\mathrm{mM}$ potassium phosphate ( $\mathrm{pH} 7.0), 1 \mathrm{mM}$ EDTA, $5 \mathrm{mM}$ dithiothreitol) and dialyzed against buffer $A$. The dialyzed sample was loaded onto a hydroxylapatite column $(2.5 \times 10$ $\mathrm{cm}$ ) (Bio-Gel HTP, Bio-Rad) that was equilibrated with buffer $A$. The column was washed with $10 \mathrm{mM}$ potassium phosphate ( $\mathrm{pH} 7.0), 1 \mathrm{mM}$ EDTA, $5 \mathrm{mM}$ dithiothreitol until the breakthrough peak of protein had been eluted. The enzyme was then eluted by a gradient up to $200 \mathrm{mM}$ potassium phosphate. The fractions containing GDH were pooled, concentrated, and buffer changed to buffer $B(20 \mathrm{mM}$ Tris- $\mathrm{HCl}(\mathrm{pH}$ 8.0), $1 \mathrm{mM}$ EDTA, $5 \mathrm{mM}$ dithiothreitol) using Amicon concentrator and then applied to a FPLC Resource-Q anion exchange column equilibrated with buffer $B$. The enzyme was then eluted using a linear gradient made with buffer $B$ in increasing concentration of $\mathrm{NaCl}$ (from $0 \mathrm{mM}$ to $100 \mathrm{mM}$ ) at $0.5 \mathrm{ml} / \mathrm{min}$. The frac- 
tions containing GDH were combined and applied to a HPLC Protein-Pak 300 SW gel filtration column $(0.15 \times 30 \mathrm{~cm})$ equilibrated with buffer $B$ and the proteins were eluted with the same buffer at $1 \mathrm{ml} / \mathrm{min}$.

The purified GDH was analyzed by sodium dodecyl sulfate/polyacrylamide gel electrophoresis (SDS/PAGE) and recognized by western blot using monoclonal antibodies against the bovine brain GDH previously produced in our laboratory (Choi et al., 1999). Protein concentration was determined by the method of Bradford (1976) using bovine serum albumin as a standard. Since $E$. coli only has an $\mathrm{NADP}^{+}$-dependent GDH (McPherson and Wootton, 1983), the enzyme assay was performed with $\mathrm{NAD}^{+}$as a coenzyme as described elsewhere (Cho et al., 1995).

\section{Enzyme assay}

GDH activity was measured spectrophotometrically at saturating conditions in the direction of reductive amination of 2-oxoglutarate by following the decrease in absorbance at $340 \mathrm{~nm}$ as described before (Cho et al., 1995). Briefly mentioned, all assays were performed in duplicate, and initial velocity data were correlated with a standard assay mixture containing $50 \mathrm{mM}$ triethanolamine $(\mathrm{pH} 8.0), 100 \mathrm{mM}$ ammonium acetate, $0.1 \mathrm{mM} \mathrm{NADH}, 2.6 \mathrm{mM}$ EDTA, and $1 \mathrm{mM}$ ADP at $25^{\circ} \mathrm{C}$. GDH concentrations were adjusted to give a measured rate of less than 0.04 absorbance units per minute. The reaction started with the addition of 2-oxoglutarate to $10 \mathrm{mM}$ final concentration. One unit of enzyme was defined as the amount of enzyme required to oxidize $1 \mu \mathrm{mol} \mathrm{NADH} / \mathrm{min}$ at $25^{\circ} \mathrm{C}$.

\section{Production of anti-human GDH mAbs}

For injection, the purified recombinant hGDH $(100 \mu \mathrm{g}$ in a volume of $200 \mu \mathrm{l}$ ) was mixed with an equal volume of Complete Freund's Adjuvant by sonication for three 15 -s bursts at $30 \%$ maximum intensity. The antigen-adjuvant mixture was injected into a female BALB/C mouse (6-8 weeks old) intraperitoneally. The first injection was followed by three booster injections at 2 to 3 -week intervals. The final injection was given 3 days before the cell fusion without adjuvant. The feeder layer cells were prepared 1 day before fusion. A 12-18 weeks old BALB/c mouse was killed by cervical dislocation, and its abdominal skin was removed carefully. Five milliliters of ice-cold $11.6 \%$ sucrose solution was injected into the peritoneal cavity, $\sim 3 \mathrm{ml}$ of the injected solution was pulled out, and peritoneal cells were collected by centrifugation for $5 \mathrm{~min}$ at $650 \mathrm{~g}$.

The fusion experiments were performed as follows (Choi et al., 1995; 1996). In brief, spleen cells released by tearing the removed spleen with fine forceps were collected in a 15-ml centrifuge tube.
Then the prepared spleen cells and SP2/0-Ag-14 mouse myeloma cells (Shulman et al., 1978) were combined, and $1 \mathrm{ml}$ of $50 \%$ polyethyleneglycol 1500 in DME (serum free) was added slowly. The fusion process was allowed to continue for $90 \mathrm{~s}$ at $37^{\circ} \mathrm{C}$ and stopped by adding DME. To avoid an osmotic shock, $1 \mathrm{ml}$ of DME was added slowly for the first $1 \mathrm{~min}$, and $2 \mathrm{ml}$ was added for the next $1 \mathrm{~min}$. For a period of $10 \mathrm{~min}$, a total of $20 \mathrm{ml}$ of DME was added. The cells were collected by centrifugation for $1 \mathrm{~min}$ at 650 $g$, suspended in $20 \mathrm{ml}$ of selective HAT medium (DME supplemented with $20 \%$ fetal bovine serum, antibiotics, and HAT) carefully by swirling, and centrifuged for $1 \mathrm{~min}$ at $650 \mathrm{~g}$. The cells were resuspended in $120 \mathrm{ml}$ of HAT medium, and $200 \mu \mathrm{l}$ of cell suspension was transferred into each well of six 96-well plates. About 2 weeks after the fusion, culture supernatants were collected and first screened by immunodot-blot analysis with purified enzyme as an antigen and then by western blot analysis. Positive clones selected by the screening methods were transferred to six-well plates, grown in tissue culture flasks $\left(75 \mathrm{~cm}^{2}\right)$, and frozen in liquid nitrogen tank. All positive clones were frozen first and cloned by limiting dilution after thawing.

\section{Cloning by limiting dilution to isolate a single specific antibody-secreting cell}

For cloning of a single specific antibody-secreting cell, aliquots of cultured cells were diluted in fresh DME medium and counted using haematocytometer. Samples to be cloned were diluted in hypoxanthine-thymidine (HT) medium to $10 \mathrm{cells} / \mathrm{ml}$. $100 \mu \mathrm{l}$ of well-suspended sample was plated in each well of 96-well plate and $100 \mu \mathrm{l}$ of fresh HT media were added. It was fed at day 5 and day 12 with two drops of medium. The cells of each well were expanded and reassayed by western blot analysis.

\section{Immunoblot analysis}

For immunodot-blotting, small squares $(1 \times 1 \mathrm{~cm})$ were drawn on a sheet of nitrocellulose paper (10x $10 \mathrm{~cm})$ and marked by numbering. One microliter of antigen solution $(0.5 \mathrm{mg} / \mathrm{ml})$ was applied onto each square and air-dried. The blots were incubated for 1 $\mathrm{h}$ in Blotto [2\% nonfat dry milk in Tris-buffered saline (TBS)], rinsed briefly with TBS, and air-dried. The blots were processed by the procedures described in Western blotting. For Western blotting, proteins separated by SDS-polyacrylamide gel electrophoresis (SDS-PAGE) were electrophoretically transferred to nitrocellulose membranes (Towbin et al., 1979), and the membranes were rinsed briefly in distilled water and air-dried. The blots were blocked with Blotto for $1 \mathrm{~h}$ at $37^{\circ} \mathrm{C}$. After rinsing with TBS, the blots were 
incubated in culture supernatants for $1 \mathrm{~h}$ and washed three times in TBS containing Tween 20 at 5 min intervals. Then, the membrane was incubated for 1 $\mathrm{h}$ at $37^{\circ} \mathrm{C}$ with horseradish peroxidase conjugated goat anti-mouse IgG antibodies, diluted $1: 5,000$ in TBS containing $0.05 \%$ Tween-20. Finally, the bound conjugate was identified by incubation of the membrane in substrate buffer $(0.5 \mathrm{mg} / \mathrm{ml}$ 4-chloro-1-naphthol in $1: 5 \mathrm{v} / \mathrm{v}$ methanol/TBS and $0.015 \% \quad \mathrm{H}_{2} \mathrm{O}_{2}$ ) for $5 \mathrm{~min}$ at room temperature.

\section{Purification of $\mathrm{mAbs}$}

For purification of $\mathrm{mAbs}, 100 \mathrm{ml}$ of the culture supernatant was centrifuged for $30 \mathrm{~min}$ at $15,000 \mathrm{~g}$ to clarify cells and insoluble aggregates and applied onto a protein A-agarose column (packed volume, $1 \mathrm{ml}$; Amersham Phamacia). The column was washed with phosphate-buffered saline (PBS) until the absorbance of unbound proteins came down to the background level, and antibodies were eluted with $0.1 \mathrm{M}$ glycine- $\mathrm{HCl}(\mathrm{pH} 2.5)$. The eluted antibodies were neutralized by addition of $1 \mathrm{M}$ Tris and dialyzed against $10 \mathrm{mM}$ Tris- $\mathrm{HCl}(\mathrm{pH} \mathrm{6.5)}$.

\section{Enzyme-inhibition test}

The effects of the mAbs on the inhibition of GDH activities were investigated by measuring catalytic activity of the GDH $(5 \mu \mathrm{g})$ after pre-incubated with purified monoclonal antibody $(50 \mu \mathrm{g})$ for $1 \mathrm{~h}$ at $37^{\circ} \mathrm{C}$. Enzymatic assays of the samples were measured by the method described in the "Enzyme assay".

\section{Epitope mapping}

One-dimensional epitope mapping was carried out according to a procedure previously described (Choi et al., 1995; 1996). Ten micrograms of purified human GDH in SDS sample buffer were mixed with an equal volume of Staphylococcus Aureus V-8 protease solution $(0.3 \mu \mathrm{g}$ in SDS sample buffer). The mixtures were assayed by SDS polyacrylamide gel and the separated peptides were transferred for immunoblotting analysis as described above.

\section{Cell culture}

Mouse neuronal cell line PC12, mouse macrophage J774A1, human hepatocellular carcinoma HepG2 (ATCC No. HB-8065), human squamous cell carcinoma SiHa (ATCC No. HTB17), and human cervical adenocarcinoma HL3T1 were obtained from Korean Cell Line Bank. All cell lines were grown in DME containing $10 \%$ FBS according to the supplier's instruction.

\section{Cross reactivities among animal brains including human and tumor cell lines}

Several animal brains from cow, pig, dog, cat, rat and chicken were removed and homogenized in $10 \mathrm{mM}$ potassium phosphate buffer containing $0.1 \mathrm{mM}$ EDTA, $1 \mathrm{mM}$ 2-mercaptoethanol and $1 \mathrm{mM}$ PMSF. The individual $25 \%(\mathrm{w} / \mathrm{v})$ homogenates were centrifuged at $10,000 \mathrm{~g}$ for $1 \mathrm{~h}$. Five microliters of each supernatant were mixed with an equal volume of $2 \times S D S$ sample buffer and boiled for $3 \mathrm{~min}$. The cooled samples were applied to SDS-PAGE and transferred to nitrocellulose membranes. After several cell lysis from various tumor cell lines such as PC12, J774A1, HepG2, SiHa, and HL3T1 were transferred nitrocellulose membranes. The blots were processed by the procedures described in Western blot. In the case of human brain, total proteins were prepared by homogenizing a small fragment of cerebral cortex removed from a 45-year old male who required a surgery after an accident.

\section{Cross reactivities among rat organs}

Several rat organs including brain, heart, lung, liver, stomach, testes, and skeletal muscle removed and homogenized in $10 \mathrm{mM}$ potassium phosphate buffer containing $0.1 \mathrm{mM}$ EDTA, $1 \mathrm{mM}$ 2-mercaptoethanol and $1 \mathrm{mM}$ PMSF. The individual $20 \%$ (w/v) homogenates were centrifuged at $10,000 \mathrm{~g}$ for $1 \mathrm{~h}$. The samples were applied onto a $10 \%$ SDS polyacrylamide gel and the separated peptides were transferred for immunoblotting analysis as described above.

\section{Other methods}

Discontinuous SDS-PAGE was carried out as described by Laemmli (1970). Spectrophotometric measurements were carried out with a Kontron model UVIKON 930 double-beam spectrophotometer.

\section{Results}

\section{Purification of the gene product}

GDH encoded by pHGDH in DE3 was purified by several chromatographic methods (see Materials and Methods). As the recombinant human GDH was readily solubilized, no detergents were required throughout the entire purification procedure. The purified GDH was estimated to be $>98 \%$ pure by SDS/PAGE (Figure $1 \mathrm{~A})$. The subunit size $(55 \mathrm{kDa})$ and the native size $(320 \mathrm{kDa})$ of the hexameric recombinant $\mathrm{GDH}$ was determined by SDS/PAGE and HPLC gel filtration chromatography (data not shown), respectively. Purified GDH protein was also similar to those of other authentic GDHs (Smith et al., 1975; Hussain et al., 1989; Cho et al., 1995). 
A

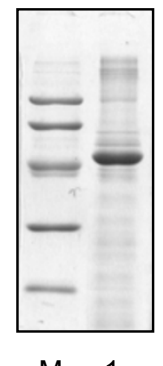

M 1
B

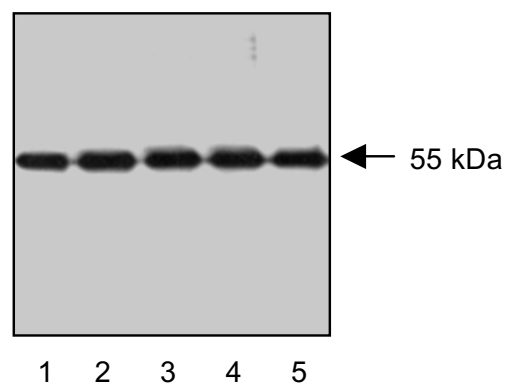

Figure 1. Expression and purification of protein $(A)$ and corresponding immunoblots $(B)$ of purified human $\mathrm{GDH}$ probed with representative hGDH mAbs: lane 1, hGDH63-10; lane 2, hGDH63-11; lane 3, hGDH60-6; lane 4, hGDH60-8; lane 5, hGDH91-14. A total of 104 were initially selected by immuno dot blot analysis. All of them recognized the purified human GDH.

\section{Production of $\mathrm{mAbs}$}

Human GDH protein, which was expressed and purified using several stages of column chromatographies, exhibited a single protein band on SDS-polyacrylamide gel (Cho et al., 2001). To enhance the immunogenicity of the protein and to obtain antibodies with a better reactivity on Western blot, purified enzyme was denatured in the presence of SDS and injected into animals. From two fusion experiments, 104 positive clones were initially screened by immunodot-blot analysis. Because goat anti-mouse IgG antibody was used as a second antibody, all monoclonal antibodies screened were of the IgG classes. Among the 104 clones hybridomas, some clones had lost the ability to produce monoclonal antibodies that reacted with the IgG protein on western blot, and thus were discarded. Twenty-four hybridomas of the 96 clones were finally selected for further study. The immunoreactivities of some representative $m A b s$ for purified human GDH are shown in Figure $1 \mathrm{~B}$.

\section{Characterization of $\mathrm{mAbs}$}

To check the specificities of the mAbs, total human brain protein was extracted, separated by SDS-PAGE, and immunoblotted with produced the mAbs. The antibodies specifically recognized a protein band of 55 kDa on SDS-PAGE (Figure 2A), which corresponded to the position of purified GDH. To determine if the mAbs inhibit GDH activity, samples of the purified enzyme were incubated with the different mAbs. Of the five representative monoclonal antibodies tested, two mAbs (hGDH63-10, hGDH63-11) inhibited enzyme activity, and the maximum extent of this inhibition observed was $58 \%$. However, no inhibition was observed following treatment with the other
A

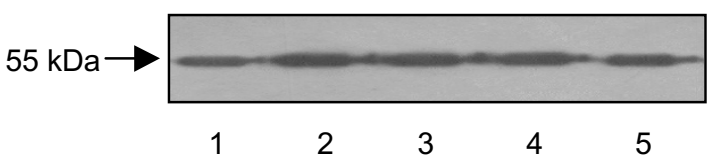

B

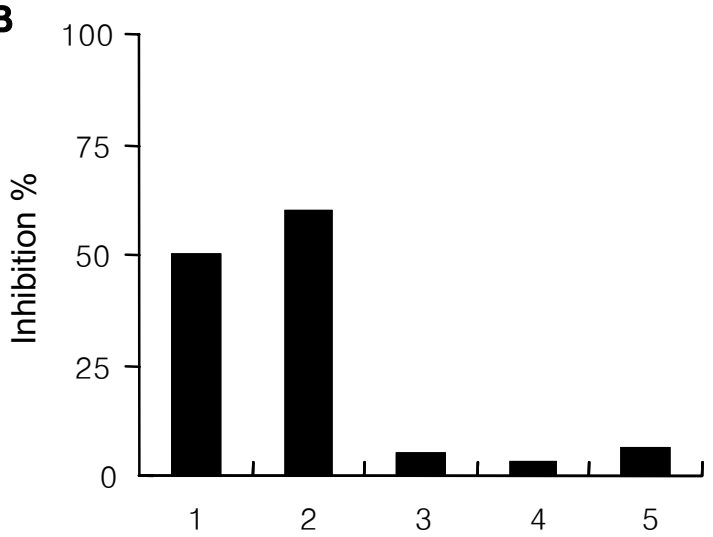

Figure 2. An immunoblots of total proteins of human brain homogenate (A) and inhibition of GDH activity by the purified $m A b(B)$ : lane 1, hGDH63-10; lane 2, hGDH63-11; lane 3, hGDH60-6; lane 4, hGDH60-8; lane 5, hGDH91-14. All mAbs specifically recognized a protein band of $55 \mathrm{kDa}$. Purified human GDH $(1 \mu \mathrm{g}$ in $10 \mu \mathrm{l}$ of 0.1 $\mathrm{M}$ potassium phosphate, $\mathrm{pH}$ 7.2) was incubated with purified mAbs $(10 \mu \mathrm{g}$ in $90 \mu \mathrm{l}$ PBS) for $1 \mathrm{~h}$ at room temperature. Then, the enzyme activities of the samples were determined as described in materials and methods. As a control, fresh culture supernatant was used, one of five mAbs (hGDH63-11) inhibited GDH activity up to a maximum of $58 \%$.

three mAbs (hGDH60-6, hGDH60-8 or hGDH91-14) (Figure 2B).

To examine further the reactivity of these mAbs, we digested purified enzyme with $\mathrm{V}-8$ protease and immunoblotted the digested samples. Among the mAbs tested, two subgroups recognizing different peptide fragments were identified (Figure 3). Thus, mAb hGDH63-10 and hGDH63-11 showed similar bands pattern indicating that these antibodies recognized the same or very similar epitopes. However, hGDH60-6, hGDH60-8, and hGDH91-14 showed different band patterns.

\section{Cross-reactivity of the mAbs with GDH from other mammalian and avian species}

In order to examine the cross-reactivities of the mAbs, we isolated the human GDH from the brains of human, cow, pig, dog, cat, rat, and chicken. Total proteins of brain homogenates were separated to SDS-PAGE, transferred on nitrocellulose membranes, and probed with the five hGDH mAbs. The immuno- 
A

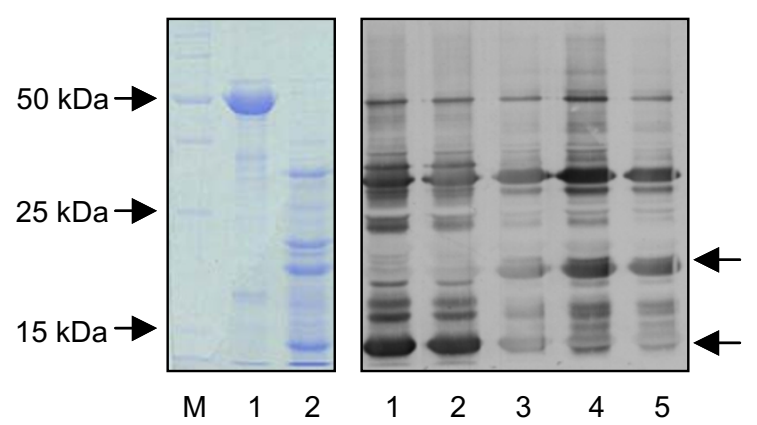

Figure 3. SDS-PAGE of purified human GDH (A) and immunoreactivity of different mAbs with purified human GDH that had been digested with Staphylococcus aureus V-8 Protease and separated by SDS-PAGE in a $15 \%$ gel (B). Lanes in $A$ is as follows: lane $M$, marker; lane 1, undigested hGHD; lane 2, digested hGDH. Lanes in $B$ is as follows: lane 1, hGDH63-10; lane 2, hGDH63-11; lane 3, hGDH60-6; lane 4, hGDH60-8; lane 5, hGDH91-14.

reactive bands on Western blot appeared as a single protein band of $55 \mathrm{kDa}$ when hGDH60-6, hGDH608, or hGDH91-14 were used as probes (Figure 4A). However, hGDH63-10 and hGDH63-11 showed no immuno-reactivity to any animal band (Figure 4B).

\section{Cross-reactivity of the mAbs with GDH from various rat organs and other animal cell lines}

Because the hGDH mAbs recognized GDH in several animals, we examined the immunoreactivities of antihGDH mAbs for GDH from various rat tissues, such as that brain and, heart, lung, liver, testes, stomach, muscle. Total protein from the various rat tissues were extracted by the methods described above and immunoblotted with hGDH60-6. As shown in Figure $5 \mathrm{~A}$, hGDH60-6 strongly recognized the same protein band on the immunoblots of total proteins of various rat tissues, i.e., brain, heart, liver, stomach and muscle. However, GDH was identified only weakly in the lung and testes.

In order to determine the immunoreactivity of GDH in tumor cell lines with the hGDH60-6, we extracted total proteins from the follwing cell-lines; mouse neuronal cells (PC12), mouse macrophage (J774A1), human hepatocellular carcinoma (HepG2), human squamous carcinoma ( $\mathrm{SiHa}$ ), and human cervical adenocarcinoma (HL3T1) cells, and immunoblotted with hGDH60-6 mAbs. These mAbs strongly recognized a GDH protein band in PC12, J774A1, and HepG2, but weak GDH bands in SiHa and HL3T1 (Figure $5 B)$.
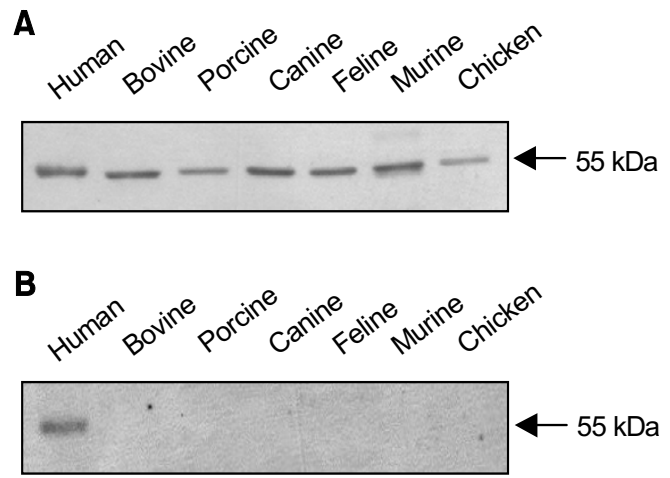

Figure 4. Cross-reactives of human GDH from some mammalian and avian species with mAbs to the human enzyme: lane 1, human; lane 2, bovine; lane 3, dog; lane 4, cat; lane 5 , rat; lane 6 , chicken; lane 7, pig. Animal brains were removed, and total proteins of the brain homogenates were immunoblotted with the GDH mAbs. (A) An immunoblot probed with mAbs hGDH60-6, hGDH60-8, hGDH91-14. (B) Corresponding immunoblot probed with $\mathrm{mAb}$ hGDH63-10, hGDH63-11.

A

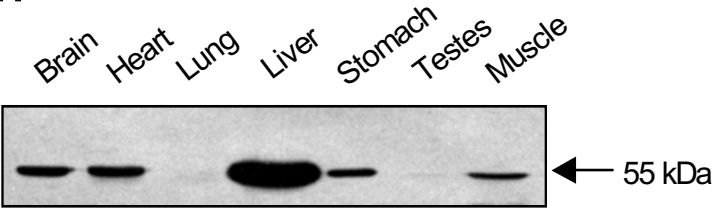

B

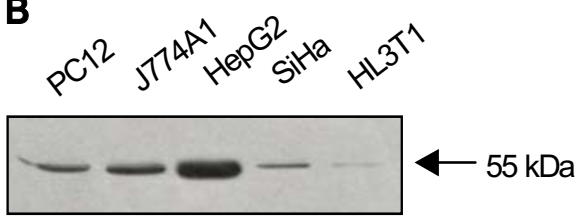

Figure 5. Cross-reactive of GDH from various rat tissues with hGDH mAbs (hGDH60-6) (A): lane 1, liver; lane 2, testis; lane 3, brain; lane 4, heart; lane 5, lung; lane 6, stomach; lane 7, muscle. Total proteins of the rat tissue homogenates were immunoblotted with the hGDH $m A b$. (B) An immunoblot of total proteins of various mammalians cell lines. Lane 1, mouse pheochromocytoma (adrenal gland) PC12; lane 2, mouse macrophage J774A1; lane 3, human hepatocellular carcinoma (liver) HepG2; lane 4, human squamous cell carcinoma (cervix) SiHa; lane 5, human adenocarcinoma (cervix) HL3T1. The cells were grown in DME containing 10\% FBS and total proteins were extracted and immunoblotted.

\section{Discussion}

GHD has been studied intensively because of its importance in GDH-dependent neurodegenerative disorders. Much evidence has shown that the enzyme is widely distributed in various tissues, but that its expressional levels and activities vary. Despite exten- 
sive biochemical studies on the mechanisms of catalysis, and the fact that a human cDNA encoding the GDH recently has been synthesized and expressed (Yoon et al., 2002), little information is available on the structure and regulation of human GDH.

In the present study, we produced a library of mAbs to human GDH. On the basis of the specificities of these mAbs, characterized by Western blot and peptide mapping analysis, they were found to recognize different epitopes of the human GDH enzyme.

It is of interest whether human GDH is immunologically different from other mammalian GDHs. Therefore, we investigated the possibility of using immunoblotting analysis for cross-reactivity testing of antihuman GDH mAbs with various animal brain proteins. Three mAbs (hGDH60-6, hGDH60-8, and hGDH91-14) strongly recognized a protein band of the same molecular weight, equivalent to $55 \mathrm{kDa}$, in all animals tested, including a human (Figure 4A), whereas hGDH63-10 and hGDH63-11 recognized only human GDH on the immunoblots of mammalian GDHs (Figure 4B). Since only one of the two subgroups of $m A b s$ was found to cross-react with human $\mathrm{GDH}$, human brain enzyme could either differ in terms of amino acid sequences or in protein structure from its counterparts in other animals. It has been suggested that conformational epitopes are more susceptible to denaturing agents, such as SDS, than linear epitopes, and conformational epitopes are usually disrupted during Western blotting (Mole, 1992). Thus, from the immunoblot results, it seems that the human enzyme differs in amino acid sequences rather than in protein structure.

When the inhibition tests were performed on human GDH using the five anti-GDH monoclonal antibodies, two monoclonal antibodies only inhibited human GDH activity (Figure 2B). The maximum extent of this inhibition was $58 \%$. These inhibitory effects of mAb hGDH63-10 or hGDH63-11 on GDH indicate that these mAbs may bind at or near the active site of the enzyme, and thus inhibit the enzyme reaction. Alternatively, the inhibition may be a result of an immobilization of the enzyme brought about by binding of the antibodies to epitopes remote from the active site. Another possibility is that the binding of antibodies causes inactivation by inducing conformational changes. These conformation changes by the enzyme by mAb binding require further investigation and an analysis of the epitope with purified antibody is warranted.

The results of epitope mapping analysis support the possibility that human GDH differs from the other animal GDHs either in terms of amino acid sequences or protein structure (Figure 3 ). It is, therefore, quite possible that there are differences between human GDH and other animal GDHs in terms of the tertiary or quaternary structures of this epitope, although GDH is known to show high sequence homology among species.

Since the hGDH mAbs recognized GDH in several mammalian brains, we examined the immunoreactivities of the anti-GDH monoclonal antibodies with various rat tissues and tumor cell lines. Immunoblotting showed that GDH in some tissues, such as brain, heart, liver, stomach and muscle, was well expressed at $55 \mathrm{kDa}$, whereas the $\mathrm{GDH}$ in the lung and testes very low levels of expression were observed (Figure $5 A)$. Among the tumor cell lines, GDH was highly recognized in neuronal cells, macrophage and hepatocarcinoma cells; however, the GDH bands in squamous and cervical carcinoma showed at low level of presence (Figure $5 \mathrm{~B}$ ). These results indicated that either GDH expression may be differently regulated in a tissue specific manner or that these differences represent structural differences of the GDH enzyme in various tissues and tumor cell lines.

In conclusion, this study describes the production and characterization of the first complete set of highaffinity monoclonal antibodies against human GDH. On the basis of the specificities of these monoclonal antibodies, characterized by Western blot analysis, inhibition studies, and epitope mapping, we suggest that there are structural differences in the human $\mathrm{GDH}$ and other mammalian GDH epitopes. Since antibodies enable the specific and sensitive detection of enzyme in tissues, they could be used for the quantitative evaluation of the enzyme's expression level. Furthermore, the availability of an inexhaustible supply of homogeneous anti-human GDH antibodies could be of great benefit in extensions of the present study, such as immunoaffinity purification, identification of expressed enzymes, and for immunohistochemical study of the brain. In particular, because human GDH mAbs recognized different epitopes of the enzyme, these human GDH mAbs could provide us with detection tools for monitoring therapy in GDH-deficient neurodegenerative disorders.

\section{Acknowledgment}

This work was supported by the National Research Laboratory (NRL; M1-9911-00-0025), Brain Neuroscience Research Grant (M1-0108-00-0019) from the Ministry of Science and Technology and by the Good Health R\&D Program Grant (01-PJ8-PG3-21304-0001) and the Korea Health 21 R\&D Project Grant (02PJ1-PG10-20706-0002) from the Ministry of Health and Welfare. And also in part by the Research Grant from Hallym University.

\section{References}

Abe T, Ishiguro SI, Saito H, Kiyosawa M, Tamai M. Partially 
deficient glutamate dehydrogenase activity and attenuated oscillatory potentials in patients with spinocerebellar degeneration. Invest Ophthalmol Vis Sci 1992;33:447-52

Ahn JY, Choi SY, Cho SW. Identification of lysine involved in inactivation of brain glutamate dehydrogenase isoproteins by o-phthalaldehyde. Biochimie 1999;81:1123-9

Bradford M. A rapid and sensitive method for the quantitation of microgram quantities of protein utilizing the principle of protein-dye binding. Anal Biochem 1976;72:248-54

Cho SW, Lee J, Choi SY. Two soluble forms of glutamate dehydrogenase isoproteins from bovine brain. Eur $\mathrm{J}$ Biochem 1995;233:340-6

Cho SW, Ahn JY, Lee J, Choi SY. Identification of a peptide of the guanosine triphosphate binding site within brain glutamate dehydrogenase isoproteins using 8-azidoguanosine triphosphate. Biochemistry 1996;35:13907-13

Cho SW, Yoon HY, Ahn JY, Choi SY, Kim TW. Identification of an $\mathrm{NAD}^{+}$binding site of brain glutamate dehydrogenase isoproteins by photoaffinity labeling. J Biol Chem 1998;273: 31125-30

Cho SW, Yoon HY, Ahn JY, Lee EY, Lee J. Cassette mutagenesis of lysine 130 of human glutamate dehydrogenase. Eur J Biochem 2001;268:3205-13

Choi EY, Park SY, Jang SH, Song MS, Cho SW, Choi SY. Production and characterization of monoclonal antibodies to bovine brain succinic semialdehyde reductase. J Neurochem 1995;64:371-7

Choi EY, Jang SH, Choi SY. Human brain GABA transaminase is immunologically distinct from those of other mammalian brain. Neurochem Int 1996;28:597-600

Choi SY, Hong JW, Song MS, Jeon SG, Bahn JH, Lee BY, Ahn JY, Cho SW. Different antigenic reactivities of bovine brain glutamate dehydrogenase isoproteins. J Neurochem $1999 ; 72: 2162-9$

Colon AD, Plaitakis A, Perakis A, Berl S, Clarke DD. Purification and characterization of a soluble and a particulate glutamate dehydrogenase from rat brain. J Neurochem 1986; 46:1811-9

Duvoisin RC, Chokroverty S, Lepore F, Nicklas W. Glutamate dehydrogenase deficiency in patients with olivopontocerebellar atrophy. Neurology 1983;33:1322-6

Hussain MH, Zannis VI, Plaitakis A. Characterization fl glutamate dehydrogenase isoproteins purufied from the cerebellum of normal subjects and patients with degenerative neurological disorders and from human neoplastic cell lines. J Biol Chem 1989;264:20730-5

Kim SW, Lee J, Song MS, Choi SY, Cho SW. Essential activesite lysine of brain glutamate dehydrogenase isoproteins. J Neurochem 1997;69:418-22

Laemmli UK. Cleavage of structural proteins during the assembly of the head of bacteriophage T4. Nature 1970;227: $680-5$
Lai JC, Cooper AJ. Brain alpha-ketoglutarate dehydrogenase complex: kinetic properties, regional distribution, and effects of inhibitors. J Neurochem 1986;47:1376-86

Lee EY, Yoon HY, Ahn JY, Choi SY, Cho SW. Identification of the GTP binding site of human glutamate dehydrogenase by cassette mutagenesis and photoaffinity labeling. J Biol Chem 2001;276:47930-6

McPherson MJ, Wootton JC. Complete nucleotide sequence of the Escherichia coli gdhA gene. Nucleic Acids Res 1983; 11:5257-66

Mole SE. Epitope mapping. In: Immunochemical Protocols, Methods in Molecular Biology, Vol. 10 (Manson M. M., ed.), 1992;105-116. Humana, Totowa

Plaitakis A, Berl S, Yahr MD. Neurological disorders associated with deficiency of glutamate dehydrogenase. Ann Neurol 1984;15:144-53

Plaitakis A, Flessas P, Natsiou AB, Shashidharan P. Glutamate dehydrogenase deficiency in cerebellar degenerations: clinical, biochemical and molecular genetic aspects. Can J Neurol Sci 1993;20:S109-16

Plaitakis A, Metaxari M, Shashidharan P. Nerve tissue-specific (GLUD2) and housekeeping (GLUD1) human glutamate dehydrogenases are regulated by distinct allosteric mechanisms: implications for biologic function. J Neurochem 2000; 75:1862-9

Schmitt A, Kugler P. Cellular and regional expression of glutamate dehydrogenase in the rat nervous system: non-radioactive in situ hybridization and comparative immunocytochemistry. Neuroscience 1999;92:293-308

Shashidharan P, Michaelidis TM, Robakis NK, Kresovali A, Papamatheakis J, Plaitakis A. Novel human glutamate dehydrogenase expressed in neural and testicular tissues and encoded by an X-linked intronless gene. J Biol Chem 1994;269: 16971-6

Shashidharan P, Clarke DD, Ahmed N, Moschonas N, Plaitakis A. Nerve tissue-specific human glutamate dehydrogenase that is thermolabile and highly regulated by ADP. J Neurochem 1997;68:1804-11

Shulman H, Whlde CD, Kohler G. A beter cell line for making hybridomas secreting specific antibodies. Nature 1978;276: 269-70

Smith E, Austin B, Blumenthal K, Nyc J. In The Enzymes (Boyer, P., ed.) Vol. 11, 1975;293-367, Academic Press, New York

Towbin H, Staehelin T, Gordon J. Eletrophoretic transfer of proteins from polyacrylamide gels to nitrocellulose sheet: procedures and some applications. Proc Natl Acad Sci USA 1979;76:4350-4.

Yoon HY, Cho EH, Kwon HY, Choi SY, Cho SW. Importance of glutamate 279 for the coenzyme binding of human glutamate dehydrogenase. J Biol Chem 2002;277:41448-54 